\title{
Assessment of HDPE Aged under DC Voltage Combined with AC Harmonic Stresses of Various Frequencies
}

\author{
Weijia Zhao, Wah Hoon Siew, Martin J Given, Edward Corr \\ University of Strathclyde \\ Department of Electronic \& Electrical Engineering \\ Glasgow G1 1XW, UK \\ Qingmin Li \\ North China Electric Power University \\ Beijing Key Laboratory of High Voltage \& EMC \\ Beijing, 102206, China \\ and Jinliang He \\ Tsinghua University \\ Department of Electrical Engineering \\ State Key Lab of Power Systems \\ Haidian, Beijing 100084, China
}

\begin{abstract}
One of the challenges on the increasing reliance on isolated renewable generation sources is the transmission of power from these sources to centers of power demand. One possible approach is the use of high voltage direct current (HVDC) transmission. The power electronic converters are key components in HVDC transmission system. The converters produce the intended DC voltage for transmission but there may also be AC harmonics superimposed. The superimposed harmonics on the HVDC may have synergistic effects and may lead to further degradation in the cable insulation. Previous research has shown that partial discharge was the main cause of degradation in polymeric insulation under AC stress. However, few publications have demonstrated the effect of combined stress on cable insulation degradation. Additionally, the most popular cable insulation material, cross-linked polyethylene (XLPE), cannot be recycled. Alternative materials which can be recycled have been proposed and one such solution could be thermoplastic materials. In this study, HDPE was investigated as a reference material for thermoplastics and their potential use as insulation in HVDC cables. In this paper the effect of frequency on HDPE degradation under superimposed stresses was studied using the following approaches; equivalent phase resolved partial discharge (PRPD) plots, fourier transform infrared spectroscopy - attenuated total reflection (FTIR-ATR) and dielectric spectroscopy (DS) measurements were carried out. The results show that during aging and with a frequency increase, the voltage of PD events increased which in turn created more polar molecule groups on the surface. The amount of polar molecule groups was found to affect $\varepsilon^{\prime}$ and $\tan \delta$, with both increasing when more polar molecules were created. The results show that applying a higher $\mathrm{AC}$ frequency enhances polymer degradation.
\end{abstract}

Index Terms - HDPE, thermo-electrical aging, voltage ratio, PRPD, FTIR-ATR, dielectric Spectroscopy.

\section{INTRODUCTION}

THE increase in demand for electrical power and the impact of $\mathrm{CO}_{2}$ emissions on climate change have led to an increasing reliance on renewable generation sources such as wind power [1-3]. Many renewable generation sources are in isolated locations far from the centers of demand and HVDC transmission system is the preferred approach to transmit energy over long distances with minimal power loss. The AC voltage output from the isolated wind farm is rectified to DC voltage at the sending end of the HVDC transmission link and the $\mathrm{DC}$ voltage inverted to an $\mathrm{AC}$ voltage that matches the grid frequency at the receiving end. The power electronic converters allow the conversion between AC/DC voltages and vice versa which is central to the operation of the HVDC link.

The converters in a HVDC system could produce 
disturbances superimposed on the DC output voltage [4-6]. The resulting interference (which is non-sinusoidal) could be regarded as AC harmonic voltages. The frequency content of the harmonic voltages depends on the switching frequency of the converter and could be up to ten times the switching frequency (tens of $\mathrm{kHz}$ ) [7].

The DC voltage combined with an AC harmonic voltage will stress the insulation and may have a synergistic effect on the lifetime of HVDC cable insulation and the insulation in cable accessories. Cable terminations and joints are the weak points in a cable system as defects or air gaps can occur during manufacture or installation. Under long-term thermo-electrical stress, the defects may cause insulation in cable accessories to fail leading to undesirable and costly system downtime. Clinton et al [8] applied voltage with $0.1 \mathrm{~Hz}$ frequency and power frequency then investigated $P D$ characteristics of an XLPE cable termination. Lee et al [9] carried out a series of experiments to determine the resultant partial discharge behavior of defects inside cable insulation at a termination. Other researchers [10-11] have introduced AC voltage and investigated the resultant PD pattern in different kinds of cable termination defects. However, there is little research investigating the behavior of cable insulation with defects when exposed to a DC voltage combined with an AC harmonic voltage.

Previously, most researchers chose oil-pressboard as the target and investigated its behavior under DC and AC combined stress. Under AC and DC combined voltages, the partial discharge feature of voids in oil-pressboard was summarized in $[12,13]$. In those investigations, the combined values of DC and AC stress were not kept constant whereas in this work of the authors, the combined values of DC and AC stress were kept constant. Their results [12, 13] demonstrated that the partial discharge inception voltage increased with a higher proportional increase in DC voltage but the corresponding PD charge decreased with an increase in the combined stress. Previous work has also been conducted on the electrical breakdown characteristics of oil-paper under AC and DC combined stresses.

Thermoplastic material is regarded as a good candidate to replace XLPE as potential cable insulation in the future [14]. Many researchers have investigated the use of thermoplastic materials to date [15-19].

The investigation of the behavior of HDPE aged under DC and AC combined stress with AC frequency variation was reported in [20]. The results demonstrated that the DC voltage could encourage cross-linking and AC voltage could encourage degradation. The degradation process developed further as the AC frequency was increased. However, there is less published work on the effect of frequency variation under combined AC\&DC voltages for cable insulation samples.

This work details an investigation into the performance of HDPE under DC and AC combined stress for high frequencies. Although HDPE is a brittle and stiff material at low temperatures, it was chosen because of its ease of availability and has characteristics close to XLPE. To simulate the cable insulation working condition the samples were also subjected to elevated temperatures. Accelerated aging was carried out. The selected aging duration is very close to time to breakdown of the material. The partial discharges emitted from the HV electrode were represented as equivalent PRPD plots and represented the aging source. FTIR-ATR and dielectric spectroscopy tests were carried out before and after each aged test sample.

\section{EXPERIMENT SET-UP 2.1 AGING SYSTEM SET-UP}

The test setup consists of stainless steel electrodes which were placed in a thermo-electrical box to control the temperature of the environment that the test sample was in.

For accelerated aging, the temperature was set at $90^{\circ} \mathrm{C}$ which is above the operating temperature of a HVDC cable.

The HDPE samples were manufactured using an extrusion molding process. Each sample was $60 \times 60 \mathrm{~mm}$ and was cut from sheets of $50 \mu \mathrm{m}$ thickness. The sample to be aged was inserted between the sphere-plane electrodes at ambient air pressure as illustrated in Figure 1.

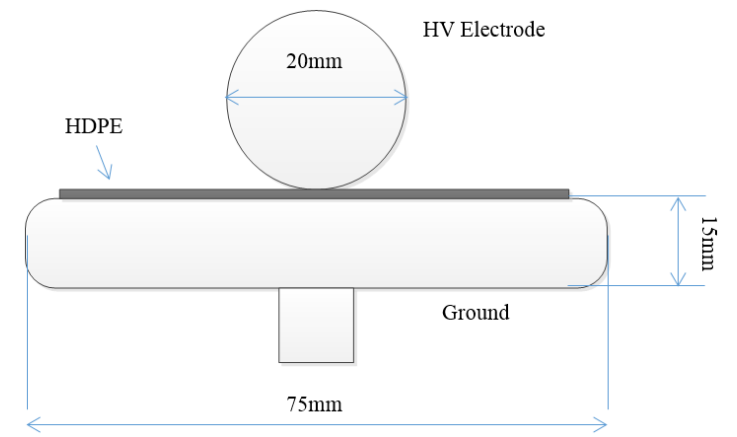

Figure 1. Electrode system of the thermo-electrical aging set-up.

The upper electrode was connected to the high voltage source and the lower electrode was connected to ground. The high voltage was generated by a signal generator feeding a power amplifier. The signal generator (Agilent 33500B Series Waveform Generator) produced a small signal of the combined voltages at high frequency and was used as an input to the power amplifier (model 50/12 produced by TRek Inc.) with a gain of 5000 to achieve the high voltage output. In this investigation, the voltage ratio of $\mathrm{AC}$ to $\mathrm{DC}$ was set to $50 \%$ (DC was $6 \mathrm{kV}$ and $\mathrm{AC}_{\max }$ was $3 \mathrm{kV})$. The AC frequency was varied. The selected frequencies were $1 \mathrm{kHz}, 1.5 \mathrm{kHz}, 2 \mathrm{kHz}$ and $2.5 \mathrm{kHz}$ and the samples were aged for 1hour. A detailed description of the voltage ratio definition is given in Section 2.2.

\subsection{VOLTAGE RATIO}

The resultant combined voltage waveform is shown in Figure 2. 


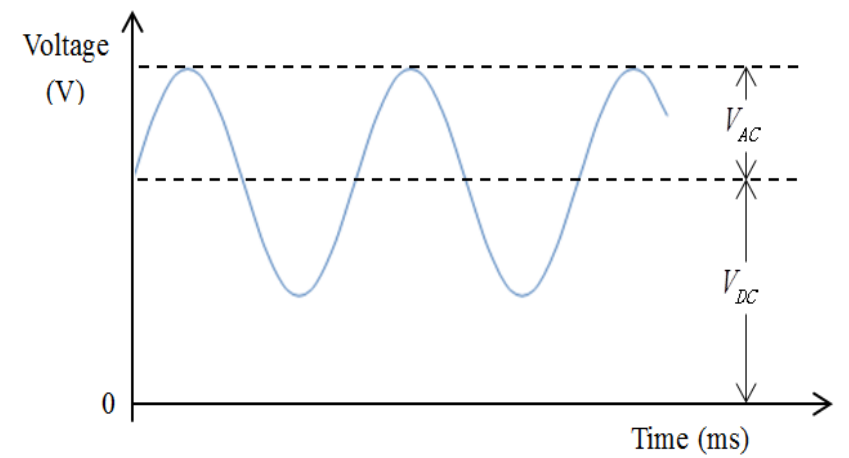

Figure 2. AC superimposed with the DC voltage waveform.

Voltage ratio $(A C \%)$ was used to describe the combined voltage stress:

$$
A C \%=\frac{V_{A C}}{V_{D C}} \times 100 \%
$$

Where, $\mathrm{V}_{\mathrm{AC}}$ is the peak value of $\mathrm{AC}$ voltage, $\mathrm{V}_{\mathrm{DC}}$ is the mean value of DC voltage.

\subsection{PRPD MEASUREMENT}

The PD detection system consisted of a current transformer (CT), coaxial cables, an oscilloscope and a computer. The CT was a high frequency current transformer (HFCT, type KH-100M) was used to measure the partial discharge (PD) signal of the polymer under combined stresses during the aging process. The PD measurement circuit is detailed in Figure 3.

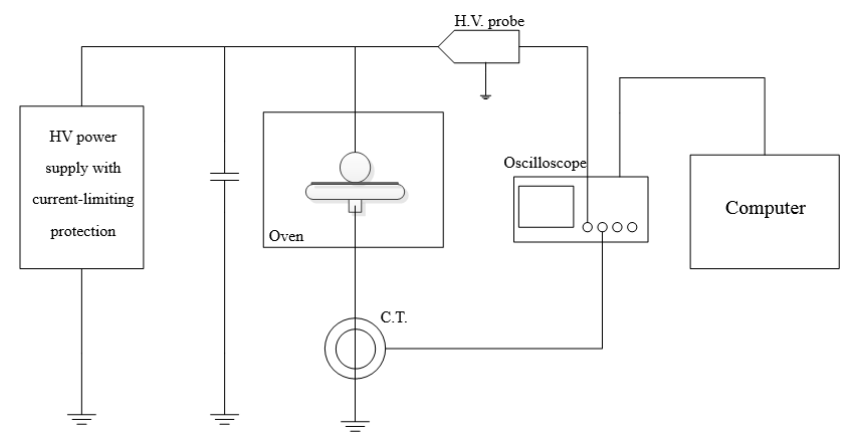

Figure 3. Diagram of PD measurement circuit.

H.V. power supply consists of signal generator and power amplifier (mentioned in the last paragraph of Chapter 2.1). For the power amplifier, the output voltage range was from 0 to $\pm 50 \mathrm{kV} \mathrm{DC}$ or peak AC. The output current range was from 0 to $\pm 12 \mathrm{~mA}$ DC or peak AC. The HFCT has a bandwidth of $0.5-120 \mathrm{MHz}$ and a sensitivity of $1-4.2 \mathrm{mV}$. The output of the HFCT was connected to the oscilloscope via a coaxial cable. The computer was connected to the oscilloscope via a USB cable and PD was recorded on a LabVIEW virtual instrument. The output of HFCT is in volts and hence the recorded PD pulses are expressed in volts in this study because it was not possible to calibrate the experimental system in terms of charge. However, this deficiency is not a problem because the authors were looking at the relative behavior after aging. During the aging period, the system captured the PD signals in packets of data every 3 seconds. The time for each PRPD measurement was 1 hour. The PD signals were related to the AC source phase so that the equivalent PRPD plots (equivalent because charge in Coulombs was not used) could be generated. PD activity is related to the phase of the applied AC voltage. In this paper, PD voltage amplitude was used to represent the PD charge. 7 samples were tested for each test condition.

\subsection{FTIR-ATR TEST}

The FTIR-ATR measurement was performed using a Nicolet iS 16 produced by Thermos Fisher, which could measure the absorbance of a sample from $350 \mathrm{~cm}^{-1}$ to 4000 $\mathrm{cm}^{-1}$. Three samples were tested for each test condition. Six separate points on the surface were measured on each sample and an average value was calculated.

\subsection{DIELECTRIC SPECTROSCOPY TEST}

The broadband dielectric spectroscopy measurement was performed using a Concept82, which was produced by NOVOCONTROL. The equipment can measure the dielectric response of the sample from $3 \mu \mathrm{Hz}$ to $3 \mathrm{GHz}$ and uses gold-plated electrodes. Prior to performing the DS measurement, each sample was placed in a gold plating machine to deposit a layer of gold through sputtering. The gold layer deposited on the upper and lower faces of the sample had a diameter of $20 \mathrm{~mm}$ to ensure good contact with the electrodes. No Guard ring was used in the DS measurement. 3 samples were tested for each test condition.

\section{RESULTS \\ 3.1 PRPD RESULTS}

The equivalent PRPD plots are shown in Figures 4-7. The $\mathrm{x}$-axis describes phase (in degrees) over the AC voltage cycle, while the $y$-axis describes the discharge amplitude in volts. The PD generally occurs in the first and third quadrants of the AC cycle.

When the superimposed frequency is increased, the discharge amplitude in the first quadrant decreases and the discharge amplitude in the third quadrant increases. As shown in Figures 4-7, the total discharge increases with increase of the superimposed frequency while the pulse repetition rate decreases with an increase in the superimposed frequency.

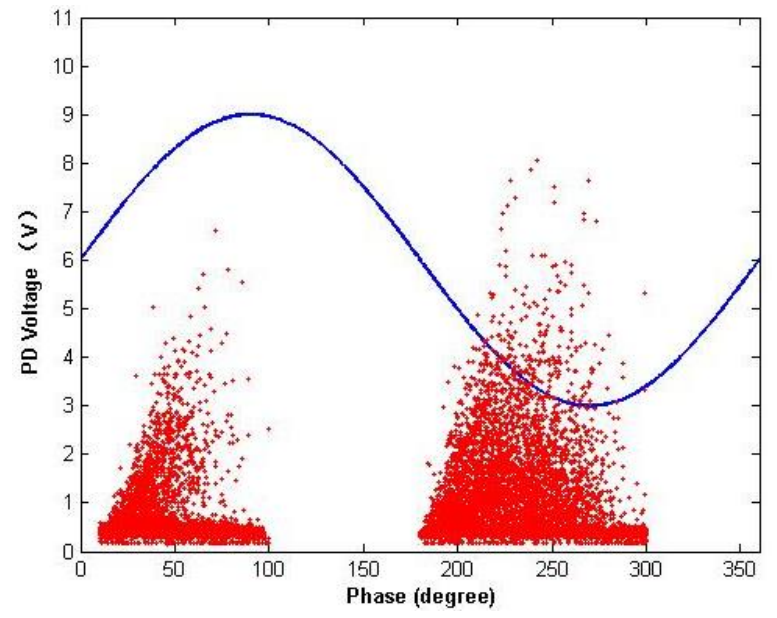

Figure 4. PRPD plot for $1 \mathrm{kHz}$ combined voltages. 


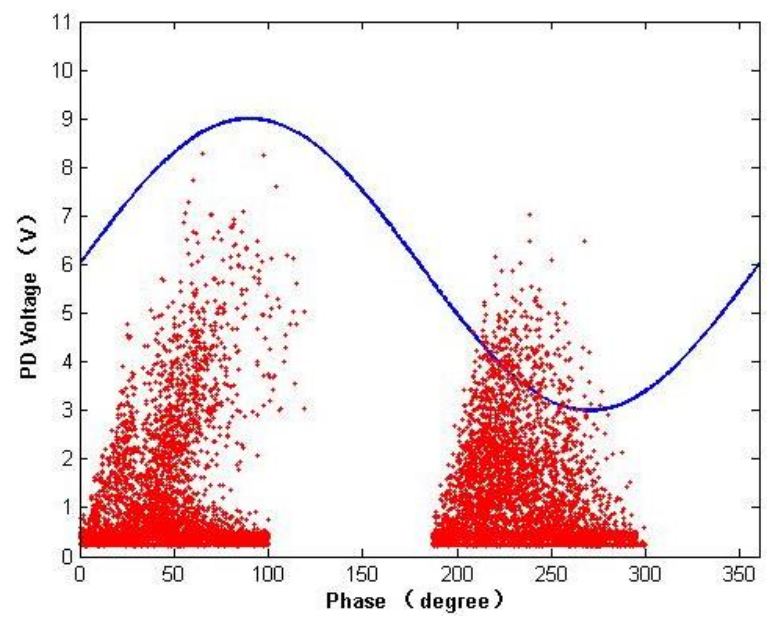

Figure 5. PRPD plot for $1.5 \mathrm{kHz}$ combined voltages.

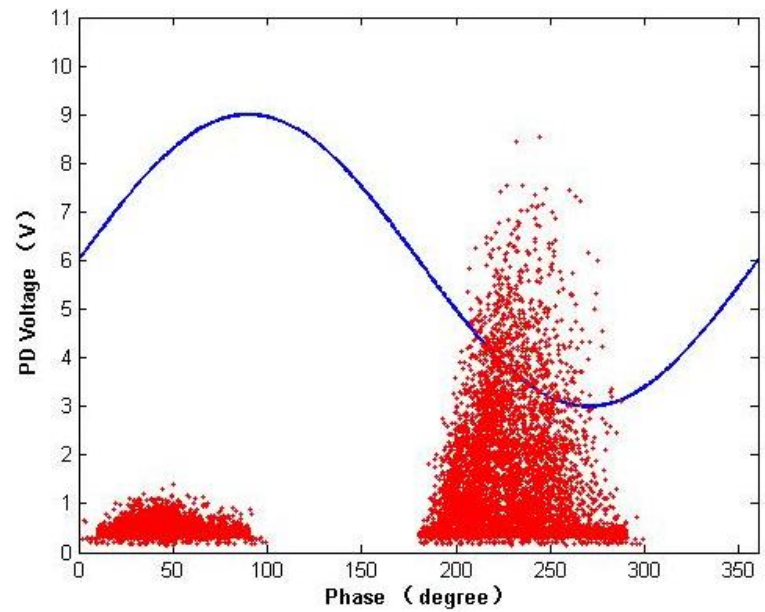

Figure 6. PRPD plot for $2 \mathrm{kHz}$ combined voltages.

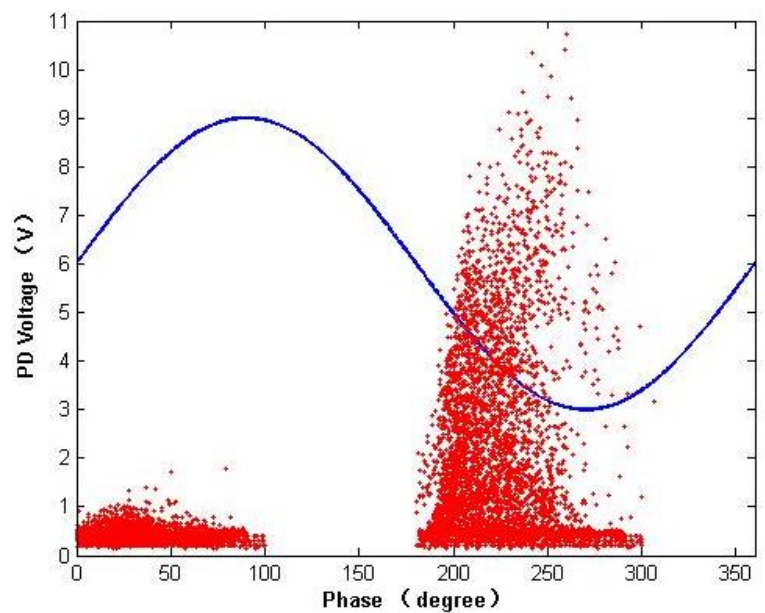

Figure 7. PRPD plot for $2.5 \mathrm{kHz}$ combined voltages.

Table 1 details the partial discharge activity in one cycle for the aging period and the four aging frequencies. Mean $(\mathrm{V})$ is the mean PD voltage, dev (V) is the standard deviation of PD voltage, discharge times (n) is the total number of PD events recorded in one cycle during the aging period over the 1 hour test. The cumulative energy is proportional to the square of voltage of each PD pulse over one cycle. The units of cumulative energy are in arbitrary units.

\begin{tabular}{|c|cccc|}
\hline \multicolumn{5}{|c|}{ Table 1. PD characteristics for the 4 frequencies used. } \\
Frequency & $\begin{array}{c}\text { Mean } \\
(\mathrm{V})\end{array}$ & $\begin{array}{c}\text { Dev } \\
\text { (V) }\end{array}$ & $\begin{array}{c}\text { Discharge } \\
\text { times (n) }\end{array}$ & $\begin{array}{c}\text { Cumulative } \\
\text { energy (V) }\end{array}$ \\
\hline $1 \mathrm{k}$ & 0.72 & 0.065 & 19030 & 13315 \\
$1.5 \mathrm{k}$ & 0.76 & 0.073 & 17534 & 13400 \\
$2 \mathrm{k}$ & 0.81 & 0.076 & 16337 & 13460 \\
$2.5 \mathrm{k}$ & 1.08 & 0.113 & 13289 & 14311 \\
\hline
\end{tabular}

Figures 8 to 10 are based on the data in Table 1. In Figure 9, it is clear that the number of discharge events has a negative relation to the frequency of the superimposed AC voltage. This is probably because as the frequency increases, the cycle time reduces and the number of PD events reduces. The mean, standard deviation and cumulative energy have a positive correlation to the superimposed frequency. When the superimposed frequency was below $2 \mathrm{kHz}$, the maximum value of PD voltage steadily increased from $8 \mathrm{~V}$ to $9 \mathrm{~V}$ and above $2 \mathrm{kHz}$ there was a dramatic increase of PD magnitude to a maximum of $10.7 \mathrm{~V}$. In terms of cumulative energy an increase of $10 \%$ is evident from $1-1.5 \mathrm{kHz}$ which is similar to the increase from $1.5-2 \mathrm{kHz}$. When the frequency was increased from $2-2.5 \mathrm{kHz}$ the cumulative energy increased by $15 \%$.

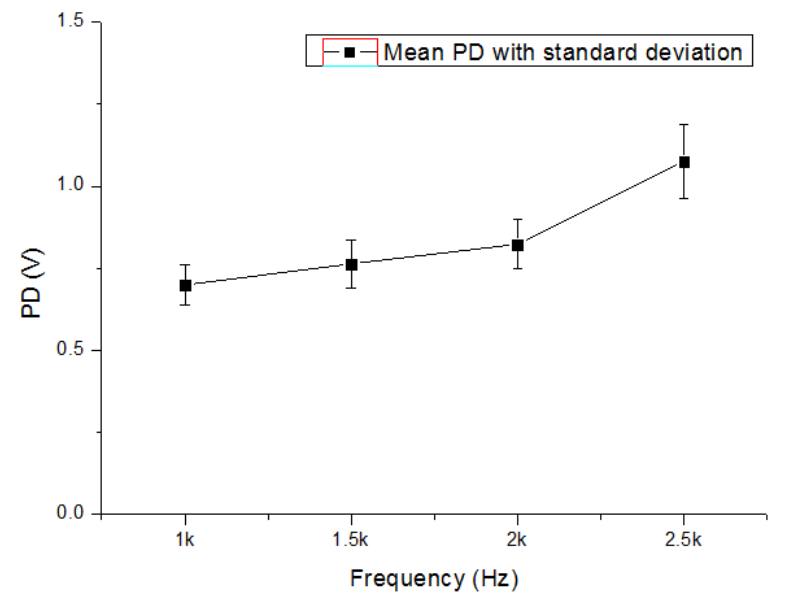

Figure 8. Mean with standard deviation of PD voltage.

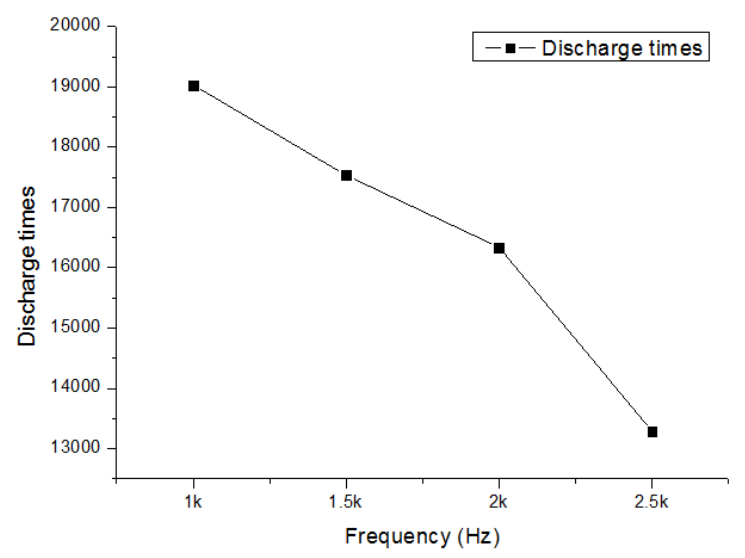

Figure 9. Discharge times. 


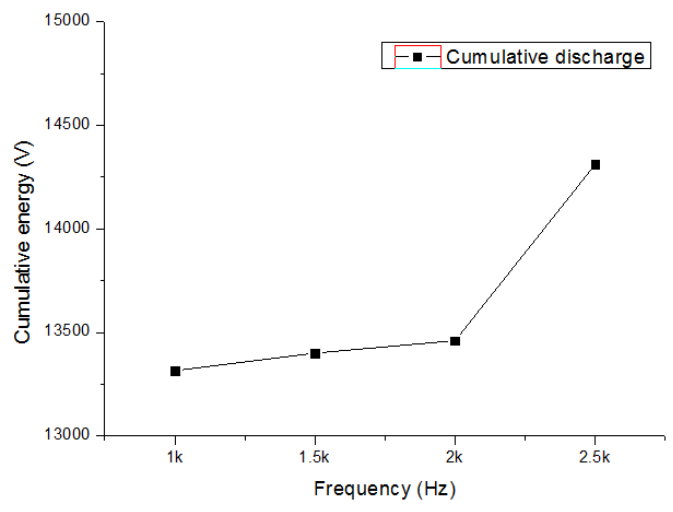

Figure 10. Cumulative PD energy.

\subsection{FTIR-ATR RESULTS}

The FTIR-ATR results are shown in Figures 11-13.

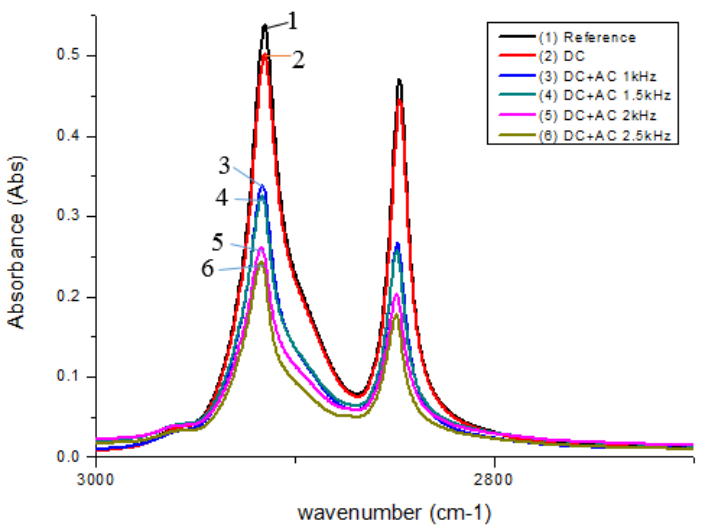

Figure 11. Detailed view of FTIR-ATR spectrum (methylene group).

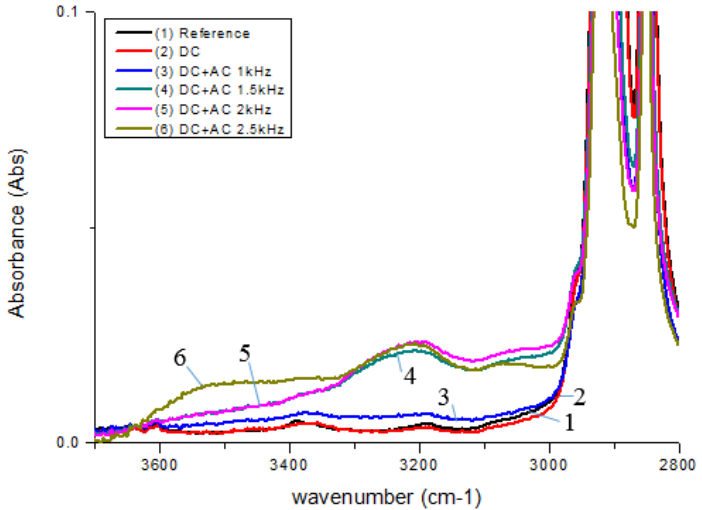

Figure 12. Detailed view of FTIR-ATR spectrum (OH-group).

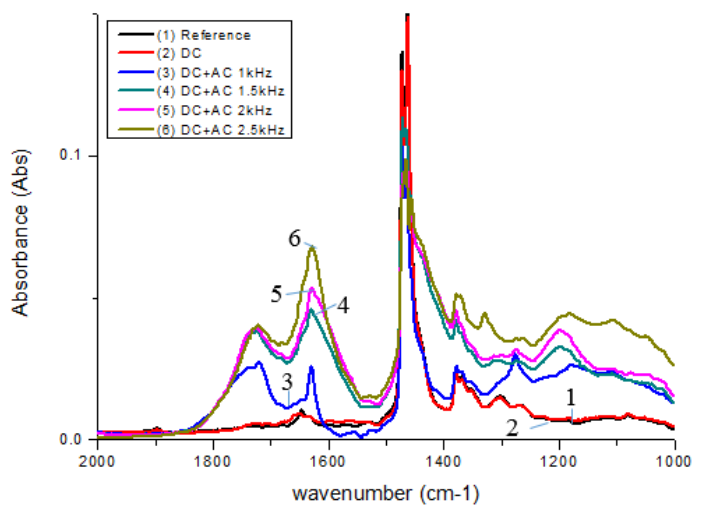

Figure 13. Detailed view of FTIR-ATR spectrum (carbonyl and C-O groups).
In the reference HDPE the FTIR-ATR spectrum consists of methylene groups, described by peaks at $2914 \mathrm{~cm}^{-1}, 2847$ $\mathrm{cm}^{-1}$ (as shown in Figure 11), $1472 \mathrm{~cm}^{-1}$ and $718 \mathrm{~cm}^{-1}$ [21]. When the HDPE samples were aged, hydroxyl group $(\mathrm{O}-\mathrm{H})$ and carbonyl groups $(\mathrm{C}=\mathrm{O})$ could occur. The $\mathrm{O}-\mathrm{H}$ group appears between $3500 \mathrm{~cm}^{-1}$ to $3000 \mathrm{~cm}^{-1}$ (Figure 12). The $\mathrm{C}=\mathrm{O}$ group appears between $1750 \mathrm{~cm}^{-1}$ to $1600 \mathrm{~cm}^{-1}$ (Figure 13). The C-O group appears at $1200 \mathrm{~cm}^{-1}$ (Figure 13).

The absorbance gives the amount of light energy absorbed by each molecular group within the test sample. The amount of each molecular group has a positive correlation to the intensity of the absorbance peak in the FTIR-ATR spectrum.

When HDPE is aged under DC conditions, the peaks of methylene groups reduced but no new molecular groups were created. When HDPE was aged under combined AC\&DC stress, the amount of methylene groups reduced significantly and it is clear that $\mathrm{C}=\mathrm{O}$ and $\mathrm{C}-\mathrm{O}$ groups increased in all samples. When the frequency was increased, the methylene groups reduced but the $\mathrm{C}=\mathrm{O}$ groups and $\mathrm{C}-\mathrm{O}$ groups increased. When frequency was increased to $2 \mathrm{kHz}$ the absorbance of the methylene groups decreased further and the $\mathrm{O}-\mathrm{H}$ groups were created.

\subsection{DIELECTRIC SPECTROSCOPY RESULTS}

The dielectric constant and dissipation factor of HDPE are shown in Figures 14 and 15, respectively. In both figures, the dielectric properties are shown for the range of $10^{-2}$ to $10^{4} \mathrm{~Hz}$.

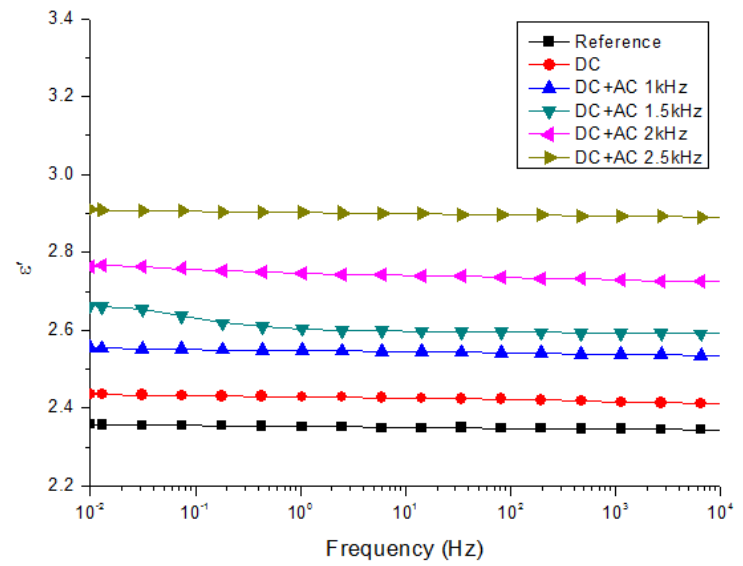

Figure 14. Dielectric constant of HDPE.

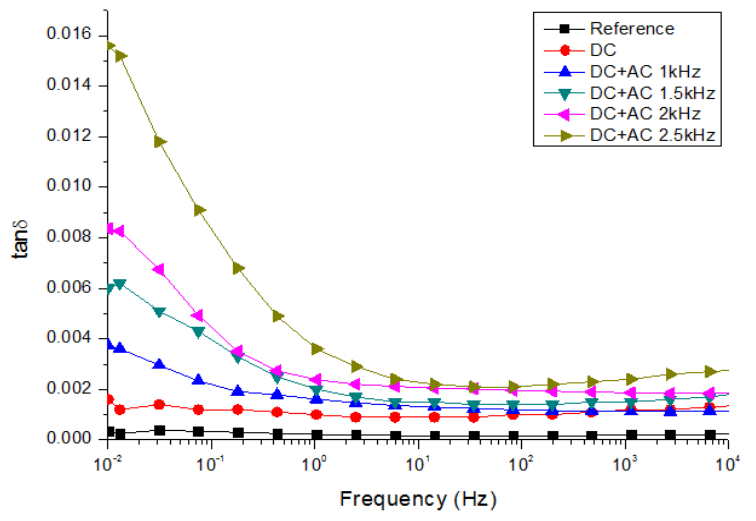

Figure 15. Dissipation factor of HDPE. 
In Figure 14, the dielectric constant $\left(\varepsilon^{\prime}\right)$ of each sample increases as the frequency decreases. $\varepsilon^{\prime}$ is also called real permittivity and it is 2.35 for the reference HDPE. The $\varepsilon^{\prime}$ of all aged samples are higher than the reference sample. When aged under DC stress, $\varepsilon^{\prime}$ increases to 2.4. The value for $\varepsilon^{\prime}$ increases further, when the samples are aged under DC and AC combined stress. In addition, $\varepsilon^{\prime}$ increased as the superimposed frequency was increased for the combined voltages. When the superimposed frequency was above 1.5 $\mathrm{kHz}$, the increase in $\varepsilon^{\prime}$ observed was larger than those aged at frequencies below $1.5 \mathrm{kHz}$.

The result agrees with the expected variation of the dielectric constant with frequency. The orientation polarization of the polar molecule is influenced by frequency. When the frequency was low the polar molecules could shift but when the frequency was high minimal shift of the polar molecules was observed.

When HDPE is aged under combined stresses degradation of the material will occur [22]. Along with the degradation process, chain scission will occur on the long molecular chain. When the long chain is broken, the new terminals may react with oxygen and create polar molecules, such as hydroxyl group $(\mathrm{O}-\mathrm{H})$ and carbonyl groups $(\mathrm{C}=\mathrm{O})$. Under external electrical stress, the polar molecule groups are easier to orientate so that as the orientation polarization increases; dielectric constant increases.

The superimposed frequency strongly affects the degradation process. Voltage stress encourages the degradation process. As the superimposed frequency increases, additional types of polar molecule groups are created. As the amount of polar molecule groups increases, the orientation polarization increases which leads to a further increase in dielectric constant. The results agree with the FTIR-ATR results. In Figure 15, the $\tan \delta$ of each sample increases as frequency decreases. For the reference sample and the sample aged by DC voltage, $\tan \delta$ is nearly constant over the frequency range. $\tan \delta$ remains constant over the frequency range of $10^{1}$ to $10^{4} \mathrm{~Hz}$, but increases rapidly with in the frequency range $10^{-2}$ to $10^{1} \mathrm{~Hz}$ for all the samples aged under combined stresses. In addition, the higher the superimposed frequency; the larger the increase observed for $\tan \delta$. When the superimposed frequency applied was less than $2 \mathrm{kHz}$, tan $\delta$ at $10^{-2} \mathrm{~Hz}$ was less than 0.009. In contrast, when the samples were aged at frequencies below $2.5 \mathrm{kHz}$, $\tan \delta$ was 0.016 at $10^{-2} \mathrm{~Hz}$. The $\tan \delta$ values of aged samples are higher than those of the reference sample.

In the high frequency range, the time period in one cycle is too short to establish relaxation polarization. There is no relaxation loss. In the low frequency range, the external electric field varies slowly and the time duration per cycle increases to allow the relaxation polarization to establish.

\section{DISCUSSIONS}

According to the results from Section 3, as the superimposed frequency increases, the PD voltage increases. FTIR-ATR and DS results show that the discharge may affect the chemical and dielectric properties of HDPE. As PD voltage increases, new kinds of polar molecule groups are created and the amount of new molecular groups increase, which is also demonstrated by changes of $\varepsilon^{\prime}$ and $\tan \delta$.

The mechanism of partial discharge could be explained as Figure 16. Assume external voltage is $\mathrm{V}_{\mathrm{S}}$ and the resulting electric field is $\mathrm{E}_{\mathrm{Q}}$.

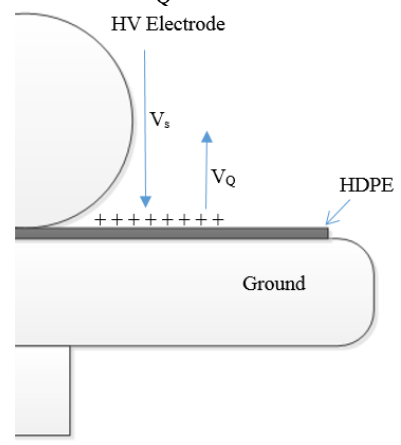

Figure 16. Mechanism of PD during aging.

In the first half cycle, when external voltage increases to the partial discharge inception voltage (PDIV), PD occurs in the air gap in the triple junction (the area between the sphere electrode and upper surface of the HDPE sample) and creates free charges. The field due to Vs drives the positive charges to the surface of the HDPE. The positive charges can establish $\mathrm{V}_{\mathrm{Q}}$. The resulting voltage $\mathrm{V}_{1}$ in triple junction is defined by:

$$
V_{1}=V_{S}-V_{Q}
$$

To reach the PDIV, $\mathrm{V}_{\mathrm{S}}$ should be increased to allow PD to occur. When the number of $P D$ events increases, $V_{Q}$ increases as well. Therefore, $\mathrm{V}_{\mathrm{Q}}$ always prevents the occurrence of further PD in the first half cycle.

When the AC voltage goes negative during the second half cycle, $\mathrm{V}_{\mathrm{Q}}$ could be higher than $\mathrm{V}_{\mathrm{S}}$ as a result of charge retention from the previous positive half cycle. Therefore, the PD voltage is much higher than the first half cycle.

With the existence of an external voltage, $\mathrm{V}_{\mathrm{Q}}$ cannot reduce to zero. The remnant $\mathrm{V}_{\mathrm{Q}}$ is not high enough to cause PDs when the AC voltage shifts to the next half cycle. Therefore, the PD voltage in the first half cycle will always be smaller. When the external voltage shifts again, charge accumulation makes $\mathrm{V}_{\mathrm{Q}}$ increase to a higher level. Therefore, in the second half of each cycle, the PD magnitude is larger.

The frequency could affect the PD pattern as well. As we know, the charge dissipation rate has a positive correlation with the ionic mobility. The slower the ionic mobility is, the lower the charge dissipation rate. Frequency can also affect the ionic mobility. The charge dissipation area in the half cycle before voltage shift follows Equation (3) [23].

$$
S=\frac{\lambda T V}{2 f}
$$

where $S$ is the charge dissipation area, $T$ is the absolute temperature, $V$ is the applied voltage, $f$ is the external frequency.

From equation (3), it is obvious that charge dissipation 
area has a negative relation to frequency. Therefore, the charge accumulates more readily when the frequency is high. As the external frequency increases, the PD voltage in the first half cycle decreases but increases in the second half cycle.

The quantity of charge created in different conditions is the main cause for the difference of FTIR-ATR and DS results of aged and reference HDPE.

\section{CONCLUSIONS}

In this paper, HDPE is the target material. PRPD, FTIR-ATR and DS measurements were carried out to determine the effect on chemical and dielectric properties of HDPE for AC\&DC combined stresses and at different frequencies.

The equivalent PRPD results show that when the external frequency was increased, the PD voltage in the first half cycle decreased but increased in the second half cycle. The mean with standard deviation of PD voltage and cumulative discharge also increased.

The FTIR-ATR results show that when the external frequency was increased, the amount of polar molecule groups increased. The polar molecule groups increased $\varepsilon^{\prime}$ of aged HDPE and $\tan \delta$ increased most in the low frequency range.

The mechanism apparent was that the inverse voltage caused by the charge always opposed the external voltage. Therefore, PD in the first half cycle is always suppressed but was encouraged in the second half cycle. The external frequency affects the PD phenomenon by altering the charge dissipation area in the triple junction. The charge dissipation area has a negative relation to external frequency. The higher frequency encouraged charge accumulation. This resulted in the PD voltage being smaller in the first half cycle but larger in the second half cycle. The quantity of charge created under the two different tests is the main cause for the difference of FTIR-ATR and DS results of aged and reference HDPE samples.

\section{ACKNOWLEDGMENT}

The facilities provided by Tsinghua University, China and North China Electric Power University, China are gratefully acknowledged.

\section{REFERENCES}

[1] N. M. Kirby, M. J. Luckett, L. Xu and W. Siepmann, "HVDC Transmission for large offshore windfarms", IEEE AC-DC Power Transmission Conf., pp. 162-168, 2001.

[2] P Bresesti, W L. Kling, R L. Hendriks and R Vailati, "HVDC Connection of Offshore Wind Farms to the Transmission System", IEEE Trans. Energy Conversion, Vol. 22, pp. 37-43, 2007.

[3] L Xu, L Yao and C Sasse, "Grid Integration of Large DFIG-Based Wind Farms Using VSC Transmission", IEEE Trans. Power Syst., Vol. 22, pp. 976-984, 2007.

[4] L Ming, F Sahlen, S Haled, G Brosig and L Palmqvis, "Impacts of High-frequency Voltage on Cable-terminations with Resistive Stressgrading", IEEE Solid Dielectr. Conf., Vol.1, pp. 300-303, 2004.

[5] H H. Sæternes, J Aakervik and S Hvidsten, "Water Treeing in XLPE Insulation at a Combined DC and High Frequency AC Stress", IEEE Electr. Insul. Conf., pp. 494-498, 2013.
[6] F Mauseth, M Amundsen and H Faremo, "Water Tree Growth of Wet XLPE Cables Stressed with DC and High Frequency AC Voltage Superimposed", IEEE Int'l Sympos. Electr. Insul. (ISEI), pp. 266-269, 2012.

[7] G Asplund, K Eriksson, J Hongbo, J Lindberg, R Pålsson and K Svensson, "DC transmission based on voltage source converters", CIGRE Session 1998, Paris, France, Paper 14-302.

[8] D. Clinton and C. Nyamupangedengu, "Partial Discharge Characterization of Cross-Linked Polyethylene Medium Voltage Power Cable Termination Defects at Very Low Frequency $(0.1 \mathrm{~Hz})$ and Power Frequency Test Voltages", IEEE Electr. Insul. Mag., Issue. 4, Vol. 32, pp. $15-23,2016$.

[9] C Lee, Y Lin, M Chiu, C Huang, S Yen and C Haeng, "Recognition of partial discharge defects in cable terminations", Condition Monitoring and Diagnosis Conf., pp. 1242 - 1245, 2008.

[10] C. Mazzetti, F. M. F. Mascioli, F. Baldini, M. Panella, R. Risica and R. Bartnikas, "Partial Discharge Pattern Recognition by Neuro-Fuzzy Networks in Heat-Shrinkable Joints and Terminations of XLPE Insulated Distribution Cables", IEEE Trans. Power Delivery, Vol. 21, pp. 1035 - 1044, 2006.

[11] Cattareeya Suwanasi, Thanapong Suwanasri, Phanupong Fuangpian and Sayan Ruankon, "Investigation on Partial Discharge of Power Cable Termination Defects Using High Frequency Current Transformer", Electrical Engineering/Electronics, Computer, Telecommunications and Information Technology Conf., pp. 1-4, 2013.

[12] B Qi, Z Wei, C Li, Y Gao and X Zhang, "Influences of Different Ratios of AC-DC Combined Voltage on Internal Gas Cavity Discharge in Oil-Pressboard Insulation", IEEE Trans. Power Delivery, Vol. 31, pp. 1026-1033, 2016

[13] B Qi, Z Wei and C Li, "Creepage Discharge of Oil-pressboard Insulation in AC-DC Composite Field: Phenomenon and Characteristics", IEEE Trans. Dielectr. Electr. Insul, Vol. 23, pp. 237-245, 2016.

[14] W Zhao, W H Siew and M J Given, "The Electrical Performance of Thermoplastic Polymers When Used As Insulation in Cables", IEEE Universities' Power Engineering Conf., pp. 1-4, 2013.

[15] Y. Zhou, J. L. He, J. Hu, X. Y. Huang, P. K. Jiang, "Evaluation of Polypropylene/Polyolefin Elastomer Blends for Potential Recyclable HVDC Cable Insulation Applications," IEEE Trans. Dielectr. Electr. Insul., Vol. 22, no. 2, pp. 673-681, 2015.

[16] B. Dang, J. L. He, J. Hu, Y. Zhou, "Tailored sPP/Silica Nanocomposite for Eco-friendly Insulation of Extruded HVDC Cable," J. Nanomaterials, 686248, 2015.

[17] Y. Zhou, J. L. He, J. Hu, B. Dang, "Surface-modified $\mathrm{MgO}$ nanoparticle enhances the mechanical and direct-current electrical characteristics of polypropylene/ polyolefin elastomer nanodielectrics," J. Appl. Polymer Sci., Vol.133, No.1, 42863, 2016.

[18] B. Dang, J. L. He, J. Hu and Y. Zhou, "Large improvement in trap level and space charge distribution of polypropylene by enhancing the crystalline-amorphous interfaces effect in blends," Polymer Int'l., Vol.65, no.4, pp.371-379, 2016.

[19] Y. Zhou, J. Hu, B. Dang and J. L. He, "Titanium oxide nanoparticle increases shallow traps to suppress space charge accumulation in polypropylene dielectrics," RSC Advances, Vol.6, pp.48720-48727, 2016.

[20] W Zhao, W H Siew, M J Given, Q Li, J He and E Corr, "Thermoplastic Materials Aging under Various Stresses", IEEE Electr. Insul. Conf., pp. 615-618, Montreal, Canada, 2016.

[21] S.L. Fa'varo, A.F. Rubira, E.C. Muniz and E. Radovanovic, "Surface modification of HDPE, PP, and PET films with $\mathrm{KMnO} 4 / \mathrm{HCl}$ solutions", Polymer Degradation and Stability, Vol. 92, pp. 1219-1226, 2007.

[22] W Wang, C Yue, J Gu, J Du, F Li and K Yang, "Status Assessment of Polymeric Materials in Mineral Oil under Electro-thermal Aging by Frequency-domain Dielectric Spectroscopy”, IEEE Trans. Dielectr. Electr. Insul, Vol.22, pp. 831-841, 2015

[23] H Shuai, "The Impact Mechanism of Frequency-Dependent Electric-Thermal Stresses on the Insulation Properties of High Frequency Power Transformer", PhD thesis, North China Electric Power University, May 2015. 


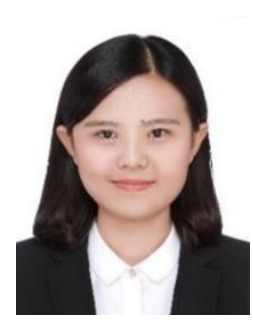

Weijia Zhao was born in Shandong Province, China in 1990. She received the B.Sc. degree ifrm the Electronic and Electrical Engineering Department of the University of Strathclyde and Shanghai University of Electric Power in 2012. Now, she is a Ph.D. degree student in University of Strathclyde.

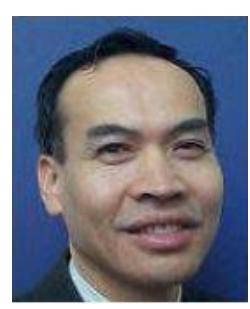

Wah H. Siew is a Reader with the Department of Electronic \& Electrical Engineering, University of Strathclyde, Glasgow, U.K. He is a Triple Alumnus of the University of Strathclyde with the B.Sc. (Hons) degree in electronic and electrical engineering; the Ph.D. degree in electronic and electrical engineering; and the M.B.A. degree. His areas of research interest include large systems electromagnetic compatibility, cable diagnostics, lightning protection, and wireless sensing systems.

$\mathrm{He}$ is a Convener of the CIGRE WG C4.2.08 and a member of the Technical Advisory Panel for the IET Professional Network on Electromagnetics. He is a Chartered Engineer and is an MIEEE and an MIEE.

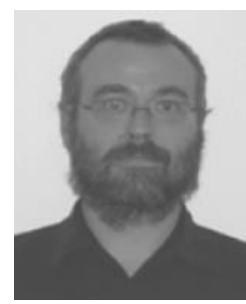

Martin J. Given (M'99-SM'11) received the degree in physics from the University of Sussex, Brighton, U.K., in 1981 and a Ph.D. degree in electronic and electrical engineering from the University of Strathclyde, Glasgow, U.K., in 1996. $\mathrm{He}$ is currently a Senior Lecturer in the Department of Electronic and Electrical Engineering at the University of Strathclyde. His research interests include ageing processes and condition monitoring in solid and liquid insulation systems, high-speed switching, and pulse power applications.

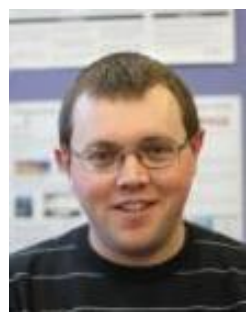

Edward Corr received the M.Eng. degree in electrical and mechanical engineering graduated from the University of Strathclyde in 2012. Corr is a $\mathrm{Ph} . \mathrm{D}$. degree student at the University of Strathclyde in the field of partial discharge detection in HVDC systems.

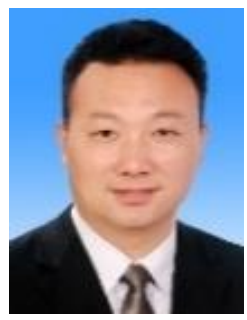

Qingmin Li (M'97) is a professor in electrical engineering at North China Electric Power University, China. He graduated from Tsinghua University, China, where he got his degrees of B.Sc. (1991), M.Sc. (1994) and Ph.D. (1999) in electrical engineering. He joined Tsinghua University as a lecturer in 1996, and came to the UK in 2000 as a postdoctoral research fellow working at Liverpool University and later at Strathclyde University. He joined Shandong University in 2003 and worked there as a professor in electrical engineering till 2011. He also worked at Arizona State University, USA, as a visiting professor in 2010. His fields of interest include high-voltage engineering, applied electromagnetics, condition monitoring and fault diagnostics, high-voltage power electronics, etc. He is a member of IET.

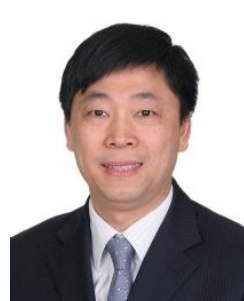

Jinliang He (M'02-SM'02-F'08) was born in Changsha, China, in 1966. He received the B.Sc. degree in electrical engineering from Wuhan University of Hydraulic and Electrical Engineering, Wuhan, China, in 1988, the M.Sc. degree in electrical engineering from Chongqing University, Chongqing, China, in 1991, and the Ph.D. degree in electrical engineering from Tsinghua University, Beijing, China, in 1994. He became a Lecturer in
1994, and an Associate Professor in 1996 in the Department of Electrical Engineering, Tsinghua University. From 1997 to 1998, he was a Visiting Scientist with the Korea Electrotechnology Research Institute, Changwon, Korea, involved in research on metal-oxide varistors and high-voltage polymeric metal-oxide surge arresters. In 2001, he was promoted to Professor at Tsinghua University. Currently, he is the Chair of the High Voltage Research Institute, Tsinghua University. His research interests include dielectric material, over voltages, electromagnetic compatibility in power systems and electronic systems, lightning protection and grounding technology. He is the author of five books and 300 technical papers. Professor He is an Associate Editor of IEEE Transactions on Dielectrics and Electrical Insulation. 